\title{
Contents of Volume 7
}

Bosch, P., see Hueting, R.

Bruinooge, G., Elteto, O., Fajth, G. and Grubben, B., Income distributions in an international perspective - The case of Hungary and the Netherlands

Duppenthaler, J.L., Map-linked data bases and their application in information processing

Elteto, G., see Bruinooge, G.

Fajth, G., see Bruinooge, G.

Fortier, C., see Michalowsky, M.

Fujikawa, K., see Gnanasekaran, K.S.

Gnanasekaran, K.S. and Fujikawa, K., Labour force and changing age structure in selected developed countries: A comparative study

Grubben, B., see Bruinooge, G.

Hoffmann, E., A labour accounting system - reflections on main concepts and principles

Hueting, R. and Bosch, P., On the correction of national income for environmental losses

Kahnert, A., Basic methodological problems in the use of monitoring and sampling for purposes of environment statistics

Latten, J.J. and Sanders, H., Dejuvenation and ageing have many social aspects

Marchand, O., Underestimation of women's participation in the labour force or new forms of inequality between men and women in the labour market? 
Martinelle, S., Fertility projection based on birth order data - A Swedish approach

Michalowsky, M., and Fortier, C., Two neglected categories of immigrants to Canada: Temporary immigrants and returning Canadians

Miscellany: Statistics on sports and exercise - The Swedish experience

N.N., Statistical tasks during the transition process in East European countries

Perry, J., Business registers - The search for quality

Plate, C.L., From flora statistics to an ecotope classification

Sanders, H., see Latten, J.J

Siampos, G.S., Trends and future prospects of the female overlife by regions in Europe

Terra Abrami, V., Aging and social expenditures in Italy: Some issues associated with population projections

Victorov, S.V., Environmental monitoring of the Gulf of Finland: an approach based on remote sensing data

Woodrow, K.A., Using census and survey data to measure undocumented immigration and emigration from the United States 